\title{
三峡库区稀有植物裸芸香的遗传 多样性和保育策略
}

\section{宋卫华 李晓东 李新伟 黄宏文 李建强”}

(中国科学院武汉植物园, 武汉 430074)

摘要 : 采用随机扩增多态性 DNA (RAPD) 对采自长江三峡库区丰都 (FD)、巫溪 (WX)、巫山(WS)、巴东 (BD)、兴 山(XS)、䄰归 (ZG) 6 个自然居群的 128 份裸芸香 (Psilopeganum sinense) 样品进行了基因组 DNA 多态性分析。用 13 条引物, 共扩增出 85 条谱带, 其中 57 条多态带, 多态位点占 $67.06 \%$ 。6 个居群的多态位点比率分别为 $25.97 \%$ (FD)、29.73\% (WX)、24.32\% (WS)、43.21\% (BD)、30.26\%(XS)、39.19\%(ZG)。用 POPGENE 1.31 版 和 NTSYS 2.10 版软件对数据进行分析 结果显示: 裸芸香具有较高的遗传多样性, 居群总的 Neís 基因多样性为 0 . 2082 总 Shannon 信息多样性指数为 0.3196 , 但各个居群内部遗传多样性较低, 居群内平均 Nei's 基因多样性为 0 . 1094 平均 Shannon 信息多样性指数为 0.1641 ; 居群间的基因分化系数 $G s t=0.5391$ 基因流 $N m=0.4275$,居群间基 因分化大于居群内基因分化, 居群间的基因交流相当少。UPGMA 聚类可将 6 个居群分为两大类: 丰都居群和以巴 东居群为地理中心呈星散状分布的其他 5 个居群。居群间的遗传距离与地理距离呈显著正相关 $(r=0.93094, P=$ 0.9861 )。最后我们初步探讨了裸芸香的濒危原因, 并提出了有效保护该物种的措施。

关键词：Psilopeganum sinense, RAPD 遗传变异，濒危机制，保护三峡库区

中图分类号 : Q16 文献标识码 : A 文章编号 : 1005-0094(2004)02-0227-10

\section{Genetic diversity and conservation strategy of Psilopeganum sinense, a rare species in the Three-Gorges Reservoir area}

\author{
SONG Wei-Hua , LI Xiao-Dong , LI Xin-Wei , HUANG Hong-Wen , LI Jian-Qiang* \\ Wuhan Botanical Garden , Chinese Academy of Sciences , Wuhan 430074
}

\begin{abstract}
The genetic diversity of 128 individuals from six Psilopeganum sinense populations from the Three-Gorges Reservoir area was analyzed using RAPD. Thirteen primers produced a total of 85 scorable markers , of which $57(67.06 \%)$ were polymorphic. The percentage of polymorphic loci of the six populations was $25.97 \%(\mathrm{FD}), 29.73 \%(\mathrm{WX}), 24.32 \%(\mathrm{WS}), 43.21 \%$ ( BD ) , 30.26\% (XS) , and $39.19 \%$ (ZG) , respectively. As analyzed by POPGENE 1.31 and NTSYS 2.10 , the genetic diversity of Psilopeganum sinense was high, with an average Nei's gene diversity of 0.2082 and an average Shannon's Information Index of 0.3196. In contrast, the genetic diversity within each population was low, with an average Nei's gene diversity of 0.1094 and an average Shannon's Information Index 0.1641. In addition , Gst was 0.5391 and $\mathrm{Nm}$ was 0.4275 ,indicating more differentiation and less gene exchange between populations than within populations. The UPGMA cluster analysis showed that the six populations were genetically clustered into two groups, of which one was the Fengdu population and the other consisted of the remaining five populations distributed geographically with the Badong population as the center. A positive correlation $(r=0.93094 p=0.9861)$ existed between geographical distance and genetic distance. Finally we discussed the cause of the endangerment status Psilopeganum sinense and proposed some management strategies for effectively protecting this species.
\end{abstract}

Key words : Psilopeganum sinense , RAPD , genetic variation , causes of endangerment , conservation , the Three-Gorges Reservoir area 
裸芸香 (Psilopeganum sinense) 隶属于芸香科 (Rutaceae) 裸芸香属, 为多年生宿根草本, 是我国特 有的单种属植物（应俊生，张玉龙，1994）, 染色体数 目 $2 n=18$, 其模式标本采自湖北西部宜昌地区。裸 芸香为重要的药用植物（黄成就,1997) ,它的果实 可入药, 有消肿、驱蛔虫之功效。此外, 全株具有清 香柑桔气味, 是一种香料原料, 有一定的经济价值。

裸芸香除了贵州赤水有分布外，主要分布于湖 北(巴东、兴山、宜昌、䄰归) 和重庆 (丰都、江津、巫 山、北碚、南川、巫溪、武隆)，其中丰都为本次调 查中所发现的新居群。裸芸香分布范围为海拔 100 $-500 \mathrm{~m}$ (应俊生, 张玉龙, 1994;王诗云等,1995;黄 成就, 1997），有相当一部分居群分布在长江三峡库 区消涨带内。三峡大坝建成后,位于库区消涨带内 的裸芸香居群将被淹没，导致这一野生资源遭受重 大损失，因而裸芸香曾被列为中国第二批拟公布珍 稀濒危保护植物（许再富,1998)。同时,库区蓄水 后将影响并可能改变库区的水文小气候以及生态环 境，对裸芸香的生存会带来潜在的危机。

裸芸香种质资源的有效保育对该物种的保存、 群落和生态系统的维持有着重要的意义 (Huang et al. ，2002)。三峡大坝建成后造成的生境片段化对 于库区内濒危植物的影响, 是植物生态学家和植物保
育遗传学家极为关注的科学问题 (Wu et al. 2003)。 物种保育成功与否, 主要在于是否保育了尽可能多的 遗传多样性，以保持其适应生境变化的潜力 (Barrett \& Kohn ,1991 Schaal et al. ，1991)。物种遗传多样性 的研究及其群体遗传结构的分析是制定并实施有效 保育策略的基础和依据( 葛颂, 1998)。尽管已有学者 对裸芸香开展了化学成分研究(袁萍等,1999) 和组织 培养技术研究（叶其刚等，1995）,但对其自然居群遗 传多样性的研究尚未见报道。

本研究通过对野外居群的调查取样,采用 RAPD 标记技术研究了三峡库区内裸芸香 6 个自然 居群遗传多样性，其目的在于:(1) 揭示裸芸香的遗 传多样性水平、居群间和居群内的遗传变异规律, 为 裸芸香就地保育优先居群的选定或迁地保护取样策 略的制定与实施提供基础数据; (2) 分析裸芸香遗 传多样性格局，以及影响遗传分化的因素，探讨其致 濒原因, 为裸芸香种质资源的综合保育策略的制定 与实施提供基础的科学依据。

\section{1 材料方法}

\section{1 材料}

裸芸香的 6 个自然居群采自其自然分布区长江 三峡库区的 6 个县市 ( 图 1 )。每个居群随机选取 20

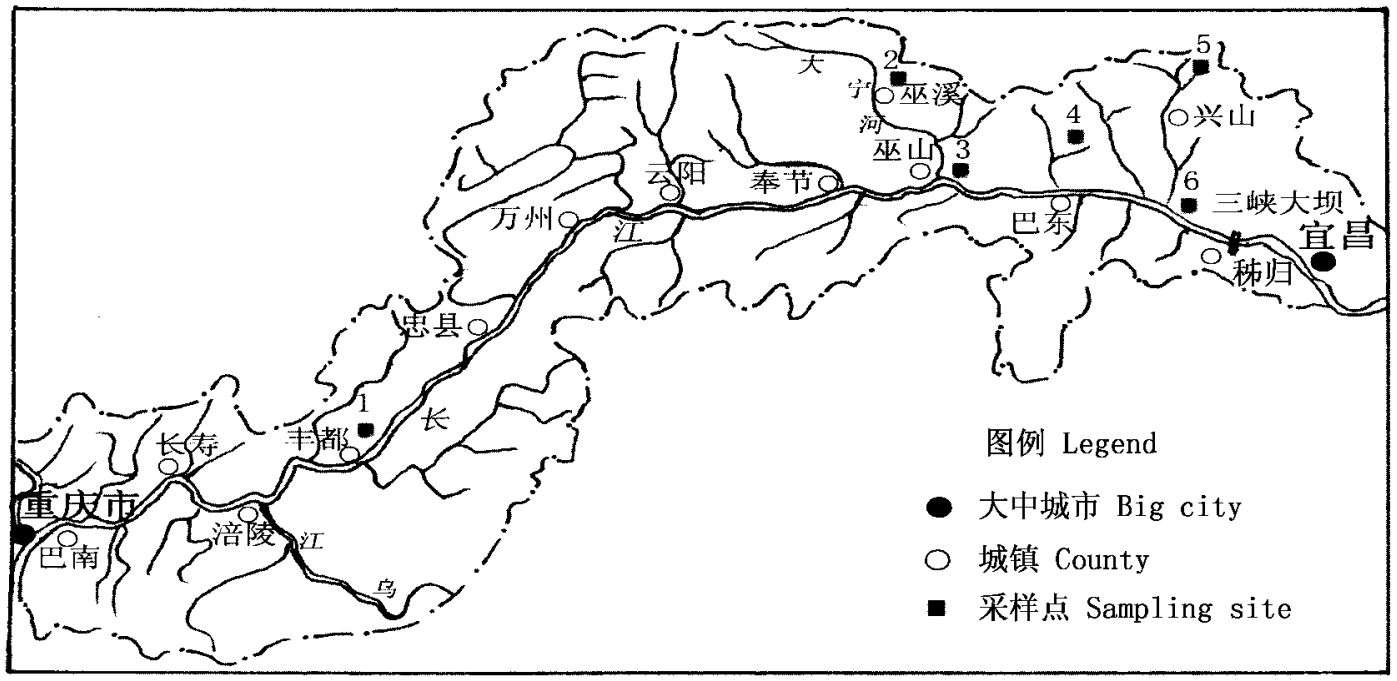

图 1 裸芸香 6 个自然居群在三峡库区的分布

Fig. 1 The distribution of the six natural populations of Psilopeganum sinense in the Three-Gorges Reservoir area 1. 丰都社坛区；2. 巫溪城厢镇；3. 巫山双龙镇；4. 巴东沿渡河；5. 兴山湘萍；6. 䄰归香溪

1. Shetan, Fengdu ;2. Chengxiang, Wuxi ;3. Shuanglong, Wushan ;4. Yanduhe , Badong ; 5. Xiangping, Xingshan ; 6. Xiangxi , Zigui 
-25 个个体, 采摘新鲜嫩叶, 分别用硅胶快速干燥 后室温保存。居群内个体间的取样尽量间隔在 $5 \mathrm{~m}$ 以上,但对破坏严重、个体较少的居群(如巴东居 群) 则采取了完全采样策略。各居群生境特点及采 样数等见表 1 。

\subsection{DNA 提取}

参照改良的 CTAB 法提取 DNA (Doyle \& Doyle ,1987 ; Whittaker et al. ,1997)。样品 DNA 经 紫外分光光度计和 $0.8 \%$ 琼脂糖凝胶电泳检测确定 DNA 质量后, 用 $0.1 \times \mathrm{TE}$ 缓冲液将 DNA 稀释至 20 $\mathrm{ng} / \mathrm{uL}$ 用于 PCR 扩增。

\section{3 引物篮选和 RAPD 扩增}

随机从 3 个居群中选取 3 个个体的 DNA 进行 引物篮选, 从 OPeron 公司 OPA1-20、OPE1-20、 OPH1-20 共 60 条随机引物中篮选出谱带清晰、多态 性强、重复性好的引物 13 条（表 2 ），用于全部 128 个 DNA 样品的正式扩增。

PCR 扩增反应参照 Williams et al. (1990)。反 应体系总体积 $25 \mu \mathrm{L}$,包括 : $10 \times$ PCR Buffer $2.5 \mu \mathrm{L}$, $\mathrm{MgCl}_{2} 2.0 \mu \mathrm{L}$,dNTP Mixture (各 $2.5 \mathrm{mM}$ ) $0.5 \mu \mathrm{L}$,
$\operatorname{TaqE}(5 \mathrm{u} / \mu \mathrm{L}) 0.4 \mu \mathrm{L}$, Primer $(5 \mathrm{pmol} / \mathrm{L}) 1 \mu \mathrm{L}$, 模 板 DNA $(20 \mathrm{ng} / \mu \mathrm{L}) 1 \mu \mathrm{L}$, 灭菌双蒸水 $\mathrm{ddH}_{2} 017.6$ $\mu \mathrm{L}$ 。最后加 $25 \mathrm{uL}$ 矿物油防止挥发。PCR 扩增体 系中, TaqE 为 Promega 公司产品, 其他为上海生工 公司产品。扩增反应在 Perkin Elmer PCR System 9600 上进行。扩增程序为 $94^{\circ} \mathrm{C}$ 预变性 $2 \mathrm{~min}$, 接 40 个循环 (每个循环依次包含 $94^{\circ} \mathrm{C} 0.5 \mathrm{~min}, 35^{\circ} \mathrm{C} 1$ $\left.\min , 72^{\circ} \mathrm{C} 1.5 \mathrm{~min}\right)$ 然后 $72^{\circ} \mathrm{C}$ 延伸 $5 \mathrm{~min}$,最后反应 终止在 $4^{\circ} \mathrm{C}$ 。扩增产物采用 $1.8 \%$ 琼脂糖凝胶电泳 检测, 在 BioRAD 电泳仪上, $1 \times \mathrm{TAE}$ 电泳缓冲液中, $3 \mathrm{~V} / \mathrm{cm}(84 \mathrm{v})$ 电压下电泳 $3 \mathrm{~h}$ 。电泳结束后, 扩增 产物先 $\mathrm{EB}(0.5 \mu \mathrm{gm} / \mathrm{L})$ 染色 $40 \mathrm{~min}$, 然后蒸馏水 $\mathrm{dH}_{2} \mathrm{O}$ 褪色 $1 \mathrm{~h}$, 接着用 UVP Polaroid 紫外观测仪观 察并一次性成像。

\section{4 数据分析}

为保证结果良好的可重复性，每次扩增至少重 复两次 稳定的扩增带用于最终的数据分析。根据 GeneRuler $^{\mathrm{TM}}$ DNA ladder Mix ( MBI Fermentas , 代号 SM0331-1) 指示的标准分子量，对照反应产物在琼 脂糖凝胶上的位置，估计扩增产物的分子量的大

表 1 裸芸香采样的位置和生境

Table 1 The habitats and localities of the samples of Psilopeganum sinense

\begin{tabular}{|c|c|c|c|c|c|}
\hline $\begin{array}{c}\text { 居群 } \\
\text { Population }\end{array}$ & $\begin{array}{l}\text { 产地 } \\
\text { Locality }\end{array}$ & $\begin{array}{c}\text { 海拔 } \\
\text { Altitude } \\
(\mathrm{m})\end{array}$ & $\begin{array}{l}\text { 生境 } \\
\text { Habitat }\end{array}$ & $\begin{array}{l}\text { 伴生植物 } \\
\text { Companion }\end{array}$ & $\begin{array}{l}\text { 取样数 } \\
\text { Sampling } \\
\text { size }\end{array}$ \\
\hline $\begin{array}{l}\text { 丰都 ( FD ) } \\
\text { Fengdu }\end{array}$ & $\begin{array}{l}\text { 重庆丰都市社坛区 } \\
\text { Shetan , Fengdu City , } \\
\text { Chongqing }\end{array}$ & 200 & $\begin{array}{l}\text { 山坡、田边 散生或丛生 } \\
\text { Hillside and fields , sparely } \\
\text { or densely grown }\end{array}$ & $\begin{array}{l}\text { 红毛悬钩子 ( Rubus pinfaensis) , 黄 } \\
\text { 荆 ( Vitex negundo), 枫 杨 ( Ptero- } \\
\text { carya stenoptera) 构树 (Broussonetia } \\
\text { papyrifera) ,龙葵 (Solanum nigrum) }\end{array}$ & 19 \\
\hline $\begin{array}{l}\text { 巫山( WS ) } \\
\text { Wushan }\end{array}$ & $\begin{array}{l}\text { 重庆巫山县双龙镇 } \\
\text { Shuanglong，Wushan } \\
\text { County , Chongqing }\end{array}$ & $110-150$ & $\begin{array}{l}\text { 山坡, 散生或丛生 } \\
\text { Hillside, sparely or dense- } \\
\text { ly grown }\end{array}$ & $\begin{array}{l}\text { 黄荆, 野塘蒿, 葳灵仙 (Clematis } \\
\text { chinensis), 探春 (Jasminum flori- } \\
\text { dum ) }\end{array}$ & 20 \\
\hline $\begin{array}{l}\text { 兴山( XS) } \\
\text { Xingshan }\end{array}$ & $\begin{array}{l}\text { 湖北兴山县湘萍乡 } \\
\text { Xiangping , Xingshan } \\
\text { County , Hubei }\end{array}$ & $240-260$ & $\begin{array}{l}\text { 山坡、路旁 散生或丛生 } \\
\text { Hillside and roadside， } \\
\text { sparely or densely grown }\end{array}$ & $\begin{array}{l}\text { 野塘蒿, 黄荆, 蒲公英 ( Taraxacum } \\
\text { mongolicum) }\end{array}$ & 21 \\
\hline $\begin{array}{l}\text { 秭归 ( ZG) } \\
\text { Zigui }\end{array}$ & $\begin{array}{l}\text { 湖北䄰归县香溪镇 } \\
\text { Xiangxi， Zigui County， } \\
\text { Hubei }\end{array}$ & 130 & $\begin{array}{l}\text { 公路旁山坡上 丛生 } \\
\text { Hillside along roads， } \\
\text { densely grown }\end{array}$ & $\begin{array}{l}\text { 野塘蕎 ,黄荆 蒲公英 臭椿 } \\
(\text { Ailanthus altissima }) \text {,艾藁 }(\text { Artemi- } \\
\text { sia argyi })\end{array}$ & 23 \\
\hline
\end{tabular}


小, 依据统一的标准, 有带的记为 1 ,无带的记为 0 ， 缺失数据记为 . ”,生成 $0 / 1$ 矩阵图。用 POPGENE 1.31 版软件 (Yeh \& Boyle，1997) 计算裸芸 香居群的多态位点百分率 (PPL)、Nei's (1973) 基因 多样性指数 (H)、Shannon's ( Lewontin，1972) 多态性 信息指数 $(I)$ 、同时计算居群内基因多样度 $(H s)$ 、居 群间基因多样度 $(D s t)$ 、居群间基因分化系数 (Gst)、 基因流 $(\mathrm{Nm})$ 以及 Neís 遗传一致度和遗传距离。并 使用 NTSYS 软件 ( Rohlf,1994) 进行了居群地理距 离与遗传距离相关性的 Mantel 检验。

\section{2 结果}

\section{1 裸芸香的 RAPD 遗传多样性}

对裸芸香 6 个自然居群的 128 个样本进行 RAPD 扩增, 共获得强度和清晰度均较好的 85 条谱 带, 其中 57 个为多态性带, 占总数的 $67.06 \%$ 。不 同引物扩增片段数目不等, $\mathrm{OPH}-02$ 扩增最多, 为 10 条(如图 2);OPH-09 扩增最少, 仅 2 条。平均每条 引物产生扩增带 6.54 条, 多态带 4.38 条。各条引 物的扩增多态性见表 2。其中, OPH-01 和 OPH-02 扩增多态位点百分率达到 100\% , 而 OPE-03 引物为 单态扩增。扩增片段长度在 $350 \sim 2600 \mathrm{bp}$ 不等。

\section{If $.31 .1 .3 .2 \ldots 1598 \div 65: 32+1$}

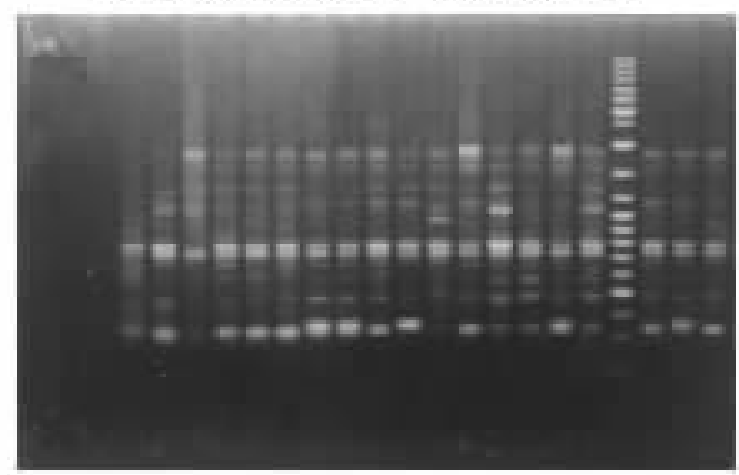

图 2 引物 OPH-02 对裸芸香样品的 RAPD 扩增谱带

Fig. 2 RAPD bands of Psilopeganum sinensis samples amplified with primer $\mathrm{OPH}-02$

Lanes $1-9$ belong to population WX ; lanes10 - 16 to WS. M : DNA ladder ( $100-3000$ bp $)$

从 PCR 扩增图谱可以看出, 丰都居群具有 4 个 特有标记（OPA01-1700、OPH02-310、OPH04-1400 和 OPH15-1600)。其中, 前 3 个为单态的特征标记， 第 4 个标记见于丰都居群 $84 \%$ 的个体; 标记 E14-
0520 在丰都居群中为单态标记, 而在其他居群中极 少见，仅见于巫山的 1 个个体和巴东的 3 个个体。 而且，A05-1600、E09-0600 和 H16-0350 在除丰都外 的其他居群中几乎为单态标记 ( 仅䄰归 2 个个体缺 少 A05-1600 ,巴东 4 个个体缺少 E09-0600) ，而丰都 居群中仅 $11 \%$ 的个体具有 H16-0350 标记,并缺少 其他 2 个标记。这些情况都表明丰都居群具有较多 的异于其他居群的遗传变异, 这一点在下面的遗传 聚类分析中也得到了证明。

裸芸香居群遗传变异结果表明裸芸香具有较高 的多态位点百分率 ( $P P L=67.06 \%)$ 、Neis 基因多样 性 $(H=0.2082)$ 与 Shannon's 信息多样性指数 ( $I=$ 0.3196 ) (表 3)。平均每个居群的总位点数、多态位 点数、多态位点百分率、Nei's 基因多样性、Shannon's 信息多样性指数分别为 $76 、 24.5 、 32.11 \% 、 0.1094$ 、 0.1641 。各居群间的遗传多样性差别比较大, 其中， 巴东 (BD) 居群具有最多的总位点数 (81)、多态位 点数 (35) 以及最高的多态位点百分率 ( $43.21 \%$ )、 Neís 基因多样性 $(H=0.1393)$ 与 Shannon's 信息多 样性指数 $(I=0.2123)$ 。而巫山 (WS) 居群的上述 各项指标均最低，分别为 $74 、 18 、 24.32 \% 、 0.0845$ 、 0.1261 说明巴东 (BD) 居群的遗传多样性在 6 个 居群中最高 巫山 (WS) 居群的遗传多样性最低。

\section{2 裸芸香居群的遗传变异的分析}

遗传变异分析表明裸芸香各居群间存在着较大 的遗传分化 (表 4)。6 个自然居群总的遗传多样性 $H t=0.2128$,其中居群内遗传多样性 $(H s)$ 为 0.0981 ,居群间的基因多样性 (Dst) 为 0.1147 ; 居群 间基因流 $(N m)$ 为 0.4275 ,小于 1 ,表明居群间基因 交流有限; 居群间的基因分化系数 (Gst) 为 0.5391 , 表明有 $53.91 \%$ 的遗传变异存在于居群间, $46.09 \%$ 的遗传变异存在于居群内, 居群间的遗传分化大于 居群内的分化。

\section{3 居群间遗传一致度与聚类分析}

裸芸香自然居群平均遗传一致度为 0.8481 ,各 个居群间的遗传一致度 ( Nei，1973) 在 $0.7284-$ 0.9558 之间（表 5 )。其中，丰都（FD）与巫溪 $(\mathrm{WX})$ 居群间的遗传一致度最低 $(I=0.7284)$ 巫溪 $(\mathrm{WX})$ 与巫山 (WS) 居群间的遗传一致度最高 $(I=$ $0.9558)$ 。丰都 (FD) 居群与其他 5 个居群间的遗传 一致度均较小 $(0.7284 \leqslant \mathrm{I} \leqslant 0.7480)$;与䄰归 $(\mathrm{ZG})$ 居 群间遗传一致度最大 $(0.7480)$;与巫溪 (WX) 居 
表 2 各个引物序列、扩增位点、多态位点数、多态位点百分率与扩增片段大小

Table 2 Primer sequences, total number of loci , percentage of polymorphic loci $(P P L)$, and length of segments

\begin{tabular}{cccccc}
\hline $\begin{array}{c}\text { 引物号 } \\
\text { Primer }\end{array}$ & $\begin{array}{c}\text { 序列 }\left(5^{\prime}-3^{\prime}\right) \\
\text { Sequences }\left(5^{\prime}-3^{\prime}\right)\end{array}$ & $\begin{array}{c}\text { 总位点数 } \\
\text { Total number of loci }\end{array}$ & $\begin{array}{c}\text { 多态位点数 } \\
\text { No. of polymorphic loci }\end{array}$ & $\begin{array}{c}\text { 多态位点百分率 } \\
P P L(\%)\end{array}$ & $\begin{array}{c}\text { 片段大小 }(\mathrm{bp}) \\
\text { Length of segments }(\mathrm{bp})\end{array}$ \\
\hline OPA01 & CAGGCCCTTC & 6 & 4 & 66.67 & $800-2000$ \\
OPA05 & AGGGGTCTTG & 9 & 5 & 55.56 & $450-1900$ \\
OPA17 & GACCGCTTGT & 6 & 5 & 83.33 & $1150-1900$ \\
OPE03 & CCAGATGCAC & 5 & 0 & 0.00 & $600-1950$ \\
OPE07 & AGATGCAGCC & 7 & 4 & 57.14 & $800-1700$ \\
OPE09 & CTTCACCGGA & 5 & 4 & 80.00 & $400-1800$ \\
OPE14 & TGCGGCTGAG & 9 & 4 & 44.44 & $450-1800$ \\
OPH01 & GGTCGGAGAA & 8 & 8 & 100.00 & $650-1800$ \\
OPH02 & TCGGACGTGA & 10 & 10 & 100.00 & $310-1200$ \\
OPH04 & GGAAGTCGCC & 5 & 3 & 60.00 & $700-1850$ \\
OPH09 & TGTAGCTGGG & 2 & 1 & 50.00 & $1000-2600$ \\
OPH15 & AATGGCGCAG & 7 & 4 & 57.14 & $690-2200$ \\
OPH16 & TCTCAGCTGG & 6 & 4 & 66.67 & $350-1100$ \\
\hline
\end{tabular}

表 3 裸芸香 6 个自然居群的遗传变异

Table 3 Genetic variation of the six natural populations of Psilopeganum sinense

\begin{tabular}{|c|c|c|c|c|c|c|}
\hline $\begin{array}{c}\text { 居群 } \\
\text { Population }\end{array}$ & $\begin{array}{l}\text { 个体数 } \\
\text { No. of } \\
\text { samples }\end{array}$ & $\begin{array}{l}\text { 总位点数 } \\
\text { Total number } \\
\text { of loci }\end{array}$ & $\begin{array}{l}\text { 多态位点数 } \\
\text { No. of poly- } \\
\text { morphic loci }\end{array}$ & $\begin{array}{l}\text { 多态位点 } \\
\text { 百分率 } \\
P P L(\%)\end{array}$ & $\begin{array}{c}\text { Neis 基 } \\
\text { 因多样性 } \\
H\end{array}$ & $\begin{array}{c}\text { Shannon' } \mathrm{s} \\
\text { 指数 } \\
I\end{array}$ \\
\hline 重庆丰都( FD) & 19 & 77 & 20 & 25.97 & 0.0913 & 0.1353 \\
\hline Standard deviation & & & & & 0.1736 & 0.2494 \\
\hline 重庆巫溪 ( WX) & 24 & 74 & 22 & 29.73 & 0.1129 & 0.1656 \\
\hline Standard deviation & & & & & 0.1885 & 0.2707 \\
\hline 重庆巫山( WS) & 20 & 74 & 18 & 24.32 & 0.0845 & 0.1261 \\
\hline Standard deviation & & & & & 0.1648 & 0.2399 \\
\hline 湖北巴东 (BD ) & 21 & 81 & 35 & 43.21 & 0.1393 & 0.2123 \\
\hline Standard deviation & & & & & 0.1837 & 0.2679 \\
\hline 湖北兴山 (XS) & 21 & 76 & 23 & 30.26 & 0.0958 & 0.1458 \\
\hline Standard deviation & & & & & 0.1664 & 0.2439 \\
\hline 湖北秭归 (ZG) & 23 & 74 & 29 & 39.19 & 0.1326 & 0.1997 \\
\hline Standard deviation & & & & & 0.1848 & 0.2708 \\
\hline 居群平均 Mean of population & 21.3 & 76 & 24.5 & 32.11 & 0.1094 & 0.1641 \\
\hline Standard deviation & & & & & 0.1770 & 0.2571 \\
\hline 物种水平 Species level & 128 & 85 & 57 & 67.06 & 0.2082 & 0.3196 \\
\hline Standard deviation & & & & & 0.1838 & 0.2641 \\
\hline
\end{tabular}

居群代号同表 1 。PPL = Percentage of polymorphic loci ; $H=$ Neis gene diversity ; $I=$ Shannon's information index ; Population codes correspond to those in Table 1 .

表 4 裸芸香 6 个自然居群基因多样性 Neis 分析

Table 4 Neís analysis of gene diversity in six natural populations of Psilopeganum sinense

\begin{tabular}{|c|c|c|c|c|}
\hline & $\begin{array}{c}\text { 总基因多样性 } \\
H t\end{array}$ & $\begin{array}{c}\text { 居群内基因多样性 } \\
H s\end{array}$ & $\begin{array}{c}\text { 基因分化系数 } \\
\text { Gst }\end{array}$ & $\begin{array}{c}\text { 基因流 } \\
\mathrm{Nm}\end{array}$ \\
\hline 平均 Mean & 0.2128 & 0.0981 & 0.5391 & 0.4275 \\
\hline 标准差 Standard deviation & 0.0346 & 0.0124 & & \\
\hline
\end{tabular}

$H t=$ total gene diversity $; H s=$ gene diversity within populations $; G s t=$ the coefficient of gene differentiation ; Nm = gene flow , Nm =0.5 $(1-G s t) / G s t$ 
表 5 裸芸香 6 个自然居群间的 Neis 遗传一致度

Table 5 Neis genetic identity of six natural populations of Psilopeganum sinense

\begin{tabular}{lccccc}
\hline & 丰都 $(\mathrm{FD})$ & 巫溪 $(\mathrm{WX})$ & 巫山( WS $)$ & 巴东 $(\mathrm{BD})$ & 兴山( XS) \\
\hline 巫溪 $(\mathrm{WX})$ & 0.7284 & & & & \\
巫山( WS) & 0.7287 & 0.9558 & & & \\
巴东 $(\mathrm{BD})$ & 0.7298 & 0.8891 & 0.8676 & & \\
兴山( XS) & 0.7450 & 0.8980 & 0.8969 & 0.8850 & \\
䄰归 $(\mathrm{ZG})$ & 0.7480 & 0.9090 & 0.8967 & 0.8888 & 0.9544 \\
\hline
\end{tabular}

居群代号同表 1。Population codes correspond to those in Table 1.

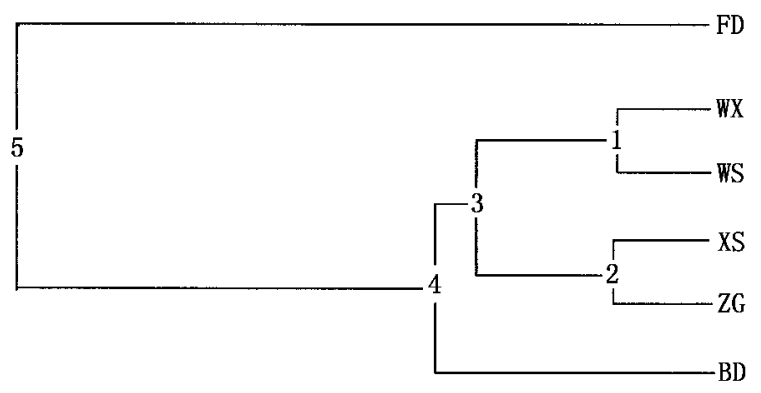

图 3 裸芸香 6 个自然居群的 Nei's 遗传一致度 UPGMA 聚 类图

Fig. 3 Dendrogram of UPGMA based on Nei's genetic identity of the six natural populations of Psilopeganum sinense. Population codes are given in Table 1 .

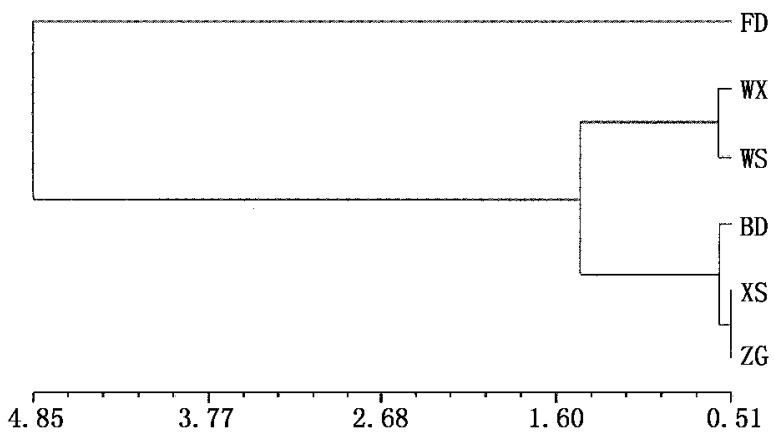

图 4 裸芸香 6 个自然居群间的地理距离聚类图

Fig. 4 Dendrogram of UPGMA based on geographic distance of the six natural populations of Psilopeganum sinense

群间的遗传一致度最小 $(0.7284)$ 。除丰都外，其他 5 个居群间的遗传一致度均相对较大 $(0.8676 \leqslant \mathrm{I} \leqslant$ 0.9558 )，尤其是巫山（WS）与巫溪 (WX)，剓归 ( ZG) 与兴山 (XS) 居群间的遗传一致度很高, 分别 为 0.9558 与 0.9544 ;巴东 (BD) 与巫山 (WS) 居群间 的遗传一致度在 5 个居群中最低 $(0.8676)$ 。这些
说明丰都居群与其他居群间的遗传差异较大。

聚类结果 (图 3 ) 表明裸芸香的 6 个自然居群明 显聚为两大支:一支仅含丰都居群 ( FD) ; 另一支包 括以巴东居群 (BD) 为地理中心的其他 5 个星散状 分布的居群。巫溪 (WX) 和巫山 (WS) 居群、兴山 (XS) 和䄰归 (ZG) 居群极近缘, 最先聚类 ; 然后这 4 个居群聚在一起 最后与巴东 (BD) 居群相聚。结果 显示地理距离较近的居群遗传上很明显地优先聚 类。

\section{4 居群间遗传距离与地理距离的相关性}

为了进一步验证裸芸香居群间的遗传距离与地 理距离的关系，我们借助于 Mantel (1967) 检验方法 进行了分析。结果表明裸芸香 6 个自然居群间的地 理距离与遗传距离呈显著的正相关, 相关系数 $(r=$ $0.93094, P=0.9861$ ) [ $P(\operatorname{random} Z<\operatorname{observed} Z)$, $P>95 \%$ 为显著相关,$P>90 \%$ 为弱显著相关]。丰 都居群 (FD) 与其他 5 个居群间地理距离相对较远, 遗传距离亦相对较远。除丰都以外的 5 个居群，以 巴东 (BD) 居群为地理中心, 呈星散状分布, 地理距 离均较近, 遗传一致度较大, 遗传距离较小。这种结 果表明裸芸香居群间的基因多样性有着显著的地域 性差异。

\section{3 讨论}

\section{1 遗传多样性}

\subsection{1 较高的遗传多样性}

一般来说, 特有或濒危物种往往遗传变异下降， 具有较低的遗传多样性 (Hamrick \& Godt , 1990 ; Falk \& Holsinger ,1991 ; Brauner et al. ,1992 洪德元 等 ,1995 裴颜龙等 ,1995; Wang et al. ,1997 ;Yan et al. 1997; Li et al. ,2002)。但是也有一些报道表明 有些特有种甚至濒危种也可能保持较高水平的遗传 
变异，具有较高的遗传多样性（Cosner \& Crawford， 1994 ;郎萍,黄宏文,1999; 邱英雄,傅承新,2001; Mattner et al. ,2002 李作洲等 2003)。

本研究结果表明裸芸香作为主要分布于三峡库 区的华中地区特有种, 具有较高的遗传多样性水平 $(P P L=67.06 \% ; H=0.2082 ; I=0.3196)$ 。与芸香 科其他物种相比, 遗传多态水平也较高 (Hogbin \& Peakall ,1999 ;张太平等 ,2001; 陈秉初等 2002)。但 是裸芸香种内居群水平上的遗传多样性水平较低 $(P P L=32.11 \% ; H=0.1094 ; I=0.1641)$ 。其中巫 山和丰都居群遗传多样性水平最低, 这可能与生境 片断化, 并且与其他居群交流困难有关。而巴东居 群因为生境较为复杂 䄰归居群因为分布较广、个体 数量较大, 它们都具有相对较高的居群遗传多样性 水平。

根据结果, 我们推测, 裸芸香很可能是一个古老 物种, 具有比较丰富的遗传基础。但随着人类活动 的日益频繁，加剧了其生境的片段化，居群间的交流 逐渐变得困难,所以虽然保留了其祖先丰富的总体 遗传多样性, 但由于各个居群个体数量变小, 近交程 度加深 (有可能存在相当程度的自交)，遗传基础趋 于一致, 造成了居群水平遗传多样性较低的现状。

\subsection{2 居群间遗传分化与基因流}

Hamrick \& Godt (1990) 运用统计学方法分析了 涉及种子植物 165 属 449 种共 653 篇酶电泳的资 料, 并探讨了分类地位、生活型、分布范围、分布地 区、繁育系统、种子扩散、生殖模式和演替阶段 8 个 内外因素对居群间遗传分化程度的影响。统计的结 果表明双子叶植物、一年生草本或短命多年生草本、 特有种、自交、靠重力或破裂扩散种子的植物、分布 于温带和亚热带的植物、处于演替早期阶段的植物 具有较大的群体分化。裸芸香居群具有较大的遗传 分化 $(G s t=0.5391)$ ，大致符合上述规律。裸芸香是 一种短命多年生的双子叶草本、华中特有单种属植 物, 其果实为蓇荂果, 顶部呈口状凹陷, 果实成熟时 开裂，种子长约 $1.5 \mathrm{~mm}$, 厚约 $1 \mathrm{~mm}$,表面无翅、无 刺, 仅具有疮状突起( 应俊生, 张玉龙, 1994; 黄成 就,1997），符合重力散播的特征。此外，对裸芸香 花蕾期植株套袋实验结果表明, 裸芸香自交可以结 实,但繁殖方式是否以自交为主尚需进一步研究确 定。

现代越来越多的研究证明,基因流强弱对群体
遗传分化具有重要影响。居群遗传学理论认为, 不 管居群大小, 只要基因流是多向性的, 当每世代居 群间迁移者多于 1 时 $(N m>1)$, 基因流就可以防止 由遗传漂变引起的居群间的遗传分化（Wright， 1931 ;Hartl \& Clark ,1989)。当基因流小于 1 时，就 不足以抵制居群内因遗传漂变而引起的居群间遗传 分化(Slatkin, 1985$)$ 。裸芸香的基因流小 $(\mathrm{Nm}=$ $0.4275)$, 很容易发生遗传漂变, 因此, 遗传漂变可 能是影响裸芸香遗传分化的重要因素。而有限的基 因流可能是由于花粉传播方式 (有小型昆虫传粉, 且是一种辅助蜜粉源植物) 和种子散播机制 (可能 靠重力和果实破裂散播) 造成的。

此外,居群间遗传距离与地理距离的 Mantel 检 验正相关性表明地理距离是影响裸芸香居群内部 遗传结构的重要因素之一。说明裸芸香遗传分化具 有一定的地域性差异, 地理隔离也对其居群遗传分 化有着比较显著的影响。

\section{2 濒危原因和保护措施}

\subsection{1 濒危原因初探}

有研究表明遗传多样性贫乏可造成居群或物种 繁衍障碍或难以适应环境的变迁而沦为濒危种 ( DeMauro ,1993 ;Huang et al. ，1998)。裸芸香虽然 具有较高的遗传多样性水平 $(P P L=67.06 \%)$, 但在 种内居群水平上遗传多样性却较低 (平均 $P P L=$ $32.11 \%$ ), 而且居群间缺乏有效的基因流( $\mathrm{Nm}=$ $0.4275)$,使得小群体的遗传多样性降低,危及整个 居群的生存。巴东居群虽然在 6 个自然居群中具有 最高的基因多样性 $(P P L=43.21 \%)$ ，但其分布和数 量有限，如果不能有效维持居群的大小和自然更新， 极有可能引起居群的退化甚至整个居群的灭绝, 使 物种的濒危程度加深。此外, 套袋实验观察结果表 明裸芸香可自交结实, 因而可能存在自交衰退现象, 不利于它适应较宽的生态幅。因此,居群内的低遗 传多样性和可能的自交衰退是裸芸香濒危的重要内 在因素。

亦有研究表明造成植物濒危的原因是人为因 素, 尤其是生境丧失、生境破坏以及过度开发利用对 物种生存的威胁最为严重 (Lande，1988)。野外考 察中发现, 裸芸香的自然生境遭到了严重的破坏 (如丰都开垦田地使得裸芸香生存地变得狭小)。 而且三峡竣工后势必进一步破坏其生境, 使得它的 栖息地更加狭小。栖息地的减少将造成个体数量的 
减小,而个体数量变小所导致的遗传漂变和自交、基 因流水平下降则可能是许多濒危物种的致濒因素 (Eriksson et al. , 1995)。所以生境片断化是裸芸香 居群分化和缩小的根本原因。

一个物种的濒危是由许多内外因素综合作用的 结果。由于我们对裸芸香知之甚少, 尚需进一步深 入探讨裸芸香的进化历史、自然选择、繁育系统、 演替阶段等问题，以进一步揭示它的濒危机制。

\subsection{2 保护措施}

裸芸香居群有相当一部分分布在长江三峡库区 消涨带。2003 年 6 月长江水位上升至 $135 \mathrm{~m}$, 虽然 我们已经对巫山( WS) 和䄰归 (ZG) 居群海拔 $135 \mathrm{~m}$ 线以下的部分个体进行了抢救性迁地保护，但仍会 有一些自然居群被淹没。对于三峡库区内即将被淹 没的裸芸香自然居群，进行迁地保护是唯一可行的 方法。1995 年有 50 多株裸芸香被迁至武汉植物 园，但并不算成功。它们虽然可以开花结果至 11 月 底, 但至今仍没有一株实生苗, 且旧植株不断死亡 (而野外考察中各个自然居群均有实生苗)。这种 情况说明裸芸香适应新生境的能力较差, 或者生长 发育的某环节甚至是繁育系统出现了障碍。所以最 好是在与它的原始生境相似的地区建立迁地保护基 地。因为如果迁移地在它们的生态幅范围内, 实行 迁地保护比较容易成功。值得注意的是稆归居群个 体较多，遗传多样性较高，迁地保护中应受到高度重 视。

由于对植物实行迁地保护要耗费较多的资源, 而且它们离开了原来的生态系统, 必然遇到诸如繁 殖能力、授粉问题、迁地保护基地的容量问题;并且 物种在植物园中存活率低, 需要考虑如何保持原来 的遗传多样性、尽量避免驯化等问题 (许再富, 1998)。所以对不被淹没的居群施行就地保护是最 佳的选择。

由于裸芸香居群间的遗传变异大于居群内遗传 变异，因此任何一个居群的丧失都将导致遗传变异 的严重流失。无论迁地保护还是就地保护，都要保 护尽可能多的居群。在居群水平上, 巴东 (BD) 居群 具有最高的遗传多样性，所以应是重点保护居群之 一; 玤都 (FD) 居群与其他居群相比,RAPD 带型较 特殊, 常会有独特的特征标记或者缺少其他居群所 具有的共有标记, 而且有时相应带的强度也会与其 他居群有显著的差别，反映了丰都居群不同于其他
居群的较大的遗传变异与遗传分化, 具有稀有基因 型，因此丰都居群具有特有标记居群的价值。优先 保护巴东的高遗传多样性和丰都居群的遗传特有性 为保护裸芸香物种遗传多样性所必需，建议最好保 护这两个居群的全部植株。

针对裸芸香总体多样性水平较高，居群内多样 性水平较低、地理隔离程度较大,基因流较小的情 况, 可以采用不同居群进行混合繁殖和相互移植来 促进该种居群的恢复。同时加强对遗传流失和易危 性的检测及就地、迁地保育技术研究 (黄宏文, 1998 )。另外要提高当地居民的保护意识,开发与 保护并重，维持居群的自然更新，保证资源的持续利 用。

致谢: 本实验在中国科学院武汉植物园植物保育遗 传学开放实验室完成。本研究得到了赵子恩、何子 灿、姜正旺和李作洲的帮助 特此致谢!

\section{参考文献}

Brrett, S. C. H. and Kohn, J. R. 1991. Genetic and evolutionary consequences of small population size in plants: implications for conservation. In: Falk, D. A. and Holsinger, K. E. (eds.), Genetics and Conservation of Rare Plants. Oxford University Press, New York, 3-30.

Brauner, S., Crawford, D. J. and Stuessy, T. F. 1992. Ribosomal DNA and RAPD variation in the rare plant family Lactoridaceae. American Journal of Botany, 79: 1436 1439

Chen, B. C. (陈秉初), Zhao, T. Q. (赵铁桥)， Ma，B. J. (马 伯军) and Shao, C. R. (邵春荣). 2002. Type delimitation and RAPD analysis of Jinhua fingered citron (Circodactylitrus medica var. sarcodactylis Swingle). Journal of Fruit Science( 果树学报)，19(4)：278-280. (in Chinese)

Cosner, M. E. and Crawford, D. L. 1994. Comparisons of isozyme diversity in three rare species of Coreopsis (Asteraceae). Systematic Botany, 19(3) : 350 - 358 .

DeMauro, M. M. 1993. Relationship of breeding system to rarity in the Lakeside Daisy (Hymenoxys acaulis var. glabra). Conservation Biology, 7:542 - 550.

Doyle, J. J. and Doyle, J. L. 1987. A rapid DNA isolation procedure for small quantities of fresh tissues. Phytochemical Bulletin, 9 (1) : $11-15$.

Eriksson, G., Namkoong, G. and Robert, J. 1995. Dynamic conservation of forest tree gene resources. Forest Genetic Resources, 23: $2-5$. 
Falk, D. A. and Holsinger, K. E. (eds.). 1991. Genetics and Conservation of Rare Plants. Oxford University Press, New York.

Ge, S. (葛颂). 1998. Review and prospect of plant population genetic structure research. In: Li, C.S. (李承森) (ed.), Advances in Plant Sciences (植物科学进展). China Higher Education Press, Beijing, 1: 1 -15. (in Chinese)

Hamrick, J. L. and Godt, M. J. W. 1990. Allozyme diversity in plant species. In: Brown, A. H. D., Clegg, M. T. , Kahler, A. L. and Weir, B. S. (eds.), Plant Population Genetics, Breeding and Genetic Resources. Sinauer, Sunderland, Mass, $43-63$.

Hartl, D. L. and Clark, A. G. 1989. Principles of Population Genetics (2nd edn.). Sinauer, Sunderland, Mass.

Hogbin, P. M. and Peakall, R. 1999. Evaluation of the contribution of genetic research to the management of the endangered plant Zieria prostrata. Conservation Biology, 13: 514 -522 .

Hong, D. Y. (洪德元)，Ge, S. (葛颂)，Zhang, D. M. (张大 明), Wang, X-Q(汪小全) and Cheng, S. Z. (程树志). 1995. Principles and approaches to studying the mechanisms of plant rarity and endangerment principles and methods of plant endangering mechanism. In: Qian, Y. Q. ( 钱 迎倩) and Zhen, R. D. (甄仁德) (eds.), Advances in Biodiversity Research-Proceedings of the 1st National Symposium on the Conservation and Sustainable Use of Biodiversity Advances in Biodiversity Research (生物多样性研究进 展一一首届全国生物多样性保护与持续利用研讨会论 文集), Chinese Science and Technology Press, Beijing, $125-133$.

Huang, C. J. (黄成就) . 1997. Flora Reipublicae Popularis Sinicae. Vol. 43 (中国植物志 $\square$ 第四十三卷). Science Press, Beijing, $89-91$.

Huang, H. W. (黄宏文). 1998. Conservation genetics and strategy for plant genetic resources. Journal of Wuhan Botanical Research(武汉植物学研究), 16(4)：346-358.

( in Chinese)

Huang, H. W., Dane, F. and Kubisiak, T. L. 1998. Allozyme and RAPD analysis of the genetic diversity and geographic variation in wild populations of the American chestnut Castanea dentate ( Fagaceae). American Journal of Botany, 85: 1013 - 1021 .

Huang, H. W., Han, X. G., Kang, L., Raven, P., Jackson, P. W. and Chen, Y. Y. 2002. Conserving native plants in China. Science, 297: 935 - 936.

Lande, R. 1988. Genetics and demography in biological conservation. Science, 241: $1455-1460$.

Lang, P. (郎萍) and Huang, H. W. (黄宏文). 1999. Genetic diversity and geographic variation in natural populations of the endemic Castanea species in China. Acta Botanica Sini$c a$ (植物学报), 41(6): 651 - 657.

Lewontin, R. C. 1972. The apportionment of human diversity. Evolutionary Biology, 6: 381 - 398.

Li, Q. M., Xu, Z.F. and He, T. H. 2002. Ex situ conservation of endangered Vatica guangxiensis (Dipterocarpaceae) in China. Biological Conservation, 106: 151 - 156.

Li, Z. Z. (李作洲), Wang, C. H. (王传华), Xu, T. Q. (许天 全), Wu, J. Q. ( 吴金清) and Huang, H. W. (黄宏文). 2003. Conservation genetics of the endemic species Myricaria laxiflora (Tamaricaceae) in the Three-Gorges Reservoir area, Hubei. Biodiversity Science (生物多样性), 11 (2) : $109-117$.

Mantal, N. A. 1967. The detection of disease clustering and a generalized regression approach. Cancer Research, 27: 209 -220 .

Mattner, J., Zanko, G., Rossetto, M., Krauss, S. L., Dixon, K. W. and Sivasithamparam, K. 2002. Conservation genetics and implications for restoration of Hemigenia exilis (Lamiaceae), a serpentine endemic from western Australia. Biological Conservation, 107: 37 - 45.

Nei, M. 1973. Analysis of gene diversity in subdivided populations. Proceedings of the National Academy of Sciences, USA, 70: 3321 - 3323.

Pei, Y. L. (裴颜龙), Zou, Y. P. (刍喻苹), Yin, Z. (尹蓁), Wang, X-Q(汪小全), Zhang, Z. X. (张志宪) and Hong, D. Y. (洪德元) . 1995. Preliminary report of RAPD analysis in Paeonia suffruticosa subsp. spontanea and Paeonia rockii. Acta Phytotaxonomica Sinica (植物分类学报), 33 (4) : $350-356$. (in Chinese)

Qiu, Y.X. (邱英雄) and Fu，C. X. (傅承新). 2001. Studies on the endangerment mechanism of and conservation strategies for Changium smyrnioides. Biodiversity Science (生物 多样性)，9(2)：151 - 156. (in Chinese)

Rohlf, F. J. 1994. NTSYS-PC. Version 2. 10. Applied Biostatistics Inc, New York.

Sanna, B. S., Gosta, E., Lena, G. and Petter, G. 1997. RAPD and morphological analysis of rare plant species $\mathrm{Vi}$ cia pisiformis (Fabaceae). Biological Journal of the Linnean Society, 61: $325-343$.

Schaal, B. A., OKane, S. L. and Rogstad, S. H. 1991. DNA variation in plant populations. Trends in Ecology and Evolution, 6: 329 - 333 .

Slatkin, M. 1985. Gene flow in natural populations. Annual Review of Ecology and Systematics, 16: 393 - 430.

Wang, S. Y. (王诗云), Zhao, Z. E. (赵子恩), Peng, F. S. (彭 辅松) and Jiang, Z. D. (蒋祖德). 1995. Conservation of Rare and Endangered Plants in Central China( 华中珍稀濒 危植物及其保存). Science Press, Beijing. 
Wang, X-Q, Zou, Y. P., Zhang, D. M., Hong, D. Y. and Liu, Z. Y. 1997. Genetic diversity analysis by RAPD in Cathaya argyrophylla Chun et Kuang. Science in China (C), 40 (2) : $145-151$.

Whittaker, D. J., Smith, G. S. and Gardner, R. C. 1997. Expression of ethylene biosynthetic genes in Actinidia chinensis fruit. Plant Molecular Biology, 34(1):45 - 55.

Williams, J. G. K., Kubelik, A. R., Livak, K. J., Rafalski, J. A. and Tingey, S. V. 1990. DNA polymorphisms amplified by arbitrary primers are useful as genetic marker. $\mathrm{Nu}$ cleic Acids Research, 18: 6531 - 6535.

Wright, S. 1931. Evolution in Mendelian population. Genetics, 16: $97-159$.

Wu, J. G., Huang, J. H., Han, X. G., Xie, Z. Q. and Gao, X. M. 2003. Three-Gorges Dam-Experiment in habitat fragmentation? Science, 300: 1239 - 1240.

Xu, Z. F. (许再富) . 1998. Principle and Methodology of ex situ Conservation for Rare and Endangered Plants (稀有濒危 植物迁地保护的原理和方法). Yunnan Science and Technology Press, Kunming.

Yan, H. J., Dai, S. L. and Wu, N. H. 1997. RAPD analysis of natural population of Acanthopanax brachypus. Cell Re- search, 7(1): $99-106$.

Ye, Q. G. (叶其刚), Xu, H. Z. (徐惠珠) and Wang, S. Y. (王诗云). 1995. Tissue culture and plantlet regeneration of Psilopeganum sinense. Plant Physiology Bulletin(植物生 理学通报), 1:43-44. (in Chinese)

Yeh, F. C. and Boyle, T. J. B. 1997. Population genetic analysis of co-dominant and dominant markers and quantitative traits. Belgian Journal of Botany, 129: 157.

Ying, T. S. (应俊生) and Zhang, Y. L. (张玉龙). 1994. Seed Plant Genera Endemic to China (中国种子植物特有属). Science Press, Beijing, 526-527. (in Chinese)

Yuan, P. (袁萍), Zhang, Y. H. (张银华), Wang, G. L. (王国 亮), Nan, P. (南蓬) and Gong, F. J. (龚复俊). 1999. A study on the chemical constituents of essential oil of an endemic and rare plant Psilopeganum sinense Hemsl. in China. Journal of Wuhan Botanical Research (武汉植物学研 究), 17(2) : 184 - 186. (in Chinese)

Zhang, T. P. (张太平), Peng, S. L. (彭少麟), Ling, D. H. (凌定厚), Li, D. (李丹) and Gan, L. S. (甘廉生). 2001. Analysis of genetic relationship among Shatianyou pomelo lines by RAPD markers. Guihaia (广西植物), 21 (3) : $247-251$. (in Chinese) 